\title{
Análise da Satisfação dos Residentes com o Turismo: o caso de uma área- destino no Algarve, Portugal
}

\section{Analysing the Satisfaction of Local Residents Towards Tourism: the case of a destination in the Algarve, Portugal}

\author{
Maria Manuela Guerreiro ${ }^{1}$ \\ Júlio da Costa Mendes ${ }^{2}$ \\ Patrícia Oom do Valle ${ }^{3}$ \\ João Albino Silva ${ }^{4}$
}

\begin{abstract}
Resumo
O objectivo deste artigo é analisar a satisfação e as atitudes dos residentes em relação ao turismo numa área destino localizada no Algarve, o mais importante destino turístico português. Este estudo teve dois objectivos centrais: determinar a importância e a satisfação dos residentes em relação a um conjunto de 30 atributos caracterizadores do destino turístico, identificados a partir da revisão de literatura, e conhecer as suas atitudes face à actividade turística no respectivo local de residência. A recolha de informação fez-se através de um inquérito por questionário e todos os atributos foram avaliados através de uma escala de Likert de cinco níveis. Finalmente, apresentam-se sugestões a ter em consideração por parte das organizações responsáveis pela gestão do destino.
\end{abstract}

Palavras-chave: residentes; impactos; atributos; satisfação; destino turístico.

\begin{abstract}
The purpose of this paper is to analyse local residents' satisfaction and attitude towards tourism in a tourism destination area located in Algarve, the most important tourism destination of the country. Using a list of 30 attributes of tourism destinations, identified in an extensive literature review on the subject, this study evaluates the attitudes of residents by taking two aspects into consideration: how residents rate the importance of each attribute for their region, and how satisfied they are with each attribute given their status of residence. All the attributes were evaluated using a measurement scale of five items. Finally, we present
\end{abstract}

\footnotetext{
1 Assistente Convidada na Faculdade de Economia da Universidade do Algarve, Doutoranda em Gestão, na especialidade de Marketing na mesma faculdade, Mestre em Gestão do Património Cultural pela Universidade do Algarve e Université Paris-8, Curso de Estudos Superiores Especializados em Marketing pela Universidade do Algarve, Licenciada em Comunicação Social, ramo Marketing, Relações Públicas e Publicidade pelo Instituto Superior de Ciências Sociais e Políticas da Universidade Técnica de Lisboa. Email: mmguerre@ualg.pt

${ }^{2}$ Professor Auxiliar da Faculdade de Economia da Universidade do Algarve, Doutorado em Gestão, especialidade de Estratégia e Comportamento Organizacional, Mestre em Ciências Económicas e Empresariais e licenciado em Gestão de Empresas. Pós-graduações em Administração Hospitalar, em Aplication of Engineering Techniques to Hospital Management e em Estudos Europeus. Investigador na área da Gestão e do Turismo (Gestão da Qualidade nos Destinos, Competitividade, Marketing, Gestão das Marcas, Comunicação e Imagem).Email: jmendes@ualg.pt

${ }^{3}$ Professora Auxiliar na Faculdade de Economia da Universidade do Algarve, Doutorada em Métodos Quatitativos Aplicados à Economia e à Gestão, na especialidade de Estatística, Mestre em Ciências Económicas e Empresariais, Licenciada em Gestão de Empresas. Email: pvalle@ualg.pt

${ }^{4}$ Professor Catedrático da Faculdade de Economia da Universidade do Algarve. Director do Programa de Doutoramento em Turismo na Universidade do Algarve. Email: jsilva@ualg.pt
} 
suggestions that should be considered by organisations involved in destination management, whether at the regional or local level.

Keywords: residents; impacts; attributes; satisfaction; tourism destination.

\section{Introdução}

Num contexto onde a concorrência é intensa e a satisfação com a experiência turística é um dos factores críticos de sucesso com maior impacto na lealdade e repetição da visita, o papel dos actores que intervêm no processo de fornecimento de produtos e serviços é determinante para o sucesso dos destinos turísticos. Entre eles situa-se a população residente que, de forma mais ou menos activa, é actor participante indissociável num cenário compósito como é o destino turístico.

A tomada de consciência desta realidade por parte de investigadores e de gestores responsáveis pela tomada de decisão no que diz respeito à gestão dos destinos turísticos, tem conduzido à emergência de uma grande multiplicidade de estudos neste domínio. De facto, o conhecimento profundo da relação entre os residentes e o sistema turístico instalado, ou que se projecta instalar numa região, vem permitir um planeamento adequado à satisfação das necessidades e desejos das populações locais o que se traduzirá em maior hospitalidade na recepção ao turista. Além disso, a sustentabilidade social, económica, cultural e ambiental do destino estará mais facilmente garantida.

É com o propósito de caracterizar a relação entre os residentes na região do ARADE, uma área constituída por quatro municípios num dos principais destinos turísticos portugueses, o Algarve, e a actividade turística que aí se instalou, que se desenvolveu este estudo. Foram definidos dois objectivos específicos: determinar a importância e a satisfação dos residentes em relação a um conjunto de 30 atributos caracterizadores do destino turístico e conhecer as suas atitudes face à actividade turística no respectivo local de residência. Este artigo pretende apresentar os resultados da investigação em torno da análise da satisfação dos residentes face ao conjunto dos 30 atributos da área-destino.

A recolha de informação fez-se através de um inquérito por questionário e todos os atributos foram avaliados através de uma escala de cinco níveis. O questionário foi administrado junto de uma amostra de residentes nos quatro municípios que constituem o ARADE e o método de amostragem utilizado foi o método das quotas independentes. Dois destes municípios - 
Portimão e Lagoa - têm uma importante linha de costa pelo que os seus principais produtos turísticos são do tipo Sol e Praia. Os restantes - Silves e Monchique -, localizados no interior, têm vindo a apostar em produtos turísticos baseados na cultura e na natureza.

\section{Revisão de literatura}

A indústria turística tem o poder de afectar a vida dos seus residentes. Este facto tem justificado, ao longo dos últimos anos, a realização de vários estudos centrados no conhecimento das atitudes dos residentes face ao turismo (ANDERECK et al, 2005; GURSOY e RUTHERFORD, 2004; KO e STUART, 2002; ANDERECK e VOGT, 2000; JUROWSKI et al, 1997; LANKFORD, 1994; PERDUE, LONG e ALLEN, 1987).

O conhecimento das atitudes e percepções dos residentes sobre os impactes do turismo nas suas comunidades é da maior importância para os responsáveis pela gestão dos lugares, quer enquanto destinos turísticos, quer enquanto locais de residência. É este conhecimento que deverá conduzir o processo de gestão dos lugares em termos de planeamento das actividades turísticas, marketing e desenvolvimento de produtos e programas turísticos (GURSOY e RUTHERFORD, 2004; TEYE, SIRAKAYA e SÖNMEZ, 2002; AP 1992).

Entretanto, vários estudos centraram-se na identificação de grupos com percepções e atitudes homogéneas em relação ao turismo (AP e CROMPTON, 1993; DAVIS et al., 1988; FREDLINE e FAULKNER, 2000; MADRIGAL, 1995; RYAN e MONTGOMERY, 1994; WILLIAMS e LAWSON, 2001; BESTARD, BUJOSA e NADAL, 2006). Este trabalho de segmentação tem-se revelado importante para a formulação de novas políticas e estratégias no domínio do turismo direccionadas para satisfazer as expectativas, simultaneamente, dos turistas e dos residentes. Neste cenário, é possível assegurar que o desenvolvimento turístico cumpre objectivos de responsabilidade social e que os impactes sociais decorrentes da actividade turística serão percebidos pela comunidade como apropriados. As interacções que se estabelecem entre a população residente e os turistas no contexto de uma experiência turística e a importância da hospitalidade nos momentos de contacto, são factores essenciais ao sucesso da actividade turística e atestam a pertinência do aprofundamento do estudo desta temática (KO e STEWART, 2002).

Apesar dos estudos desenvolvidos ao longo da última década acerca das atitudes dos residentes face ao turismo, não está compreendida a relação entre as percepções dos residentes acerca dos impactes do turismo e a satisfação da comunidade. A este propósito, Ap 
e Crompton (1992) e Ko e Stewart (2002) consideram que tal situação limita a compreensão do comportamento dos residentes face aos impactes do turismo.

A base teórica predominante da maioria dos estudos desenvolvidos sobre esta temática tem sido a Social Exchange Theory (PERDUE, LONGO e ALLEN, 1990; AP, 1992; MADRIGAL, 1995; JUROWSKI et al, 1997; ANDEREK et al, 2005). Trata-se de uma "teoria sociológica generalista preocupada com a compreensão das relações de troca que se estabelecem entre indivíduos e grupos numa situação de interacção" (AP, 1992:668). Para Perdue, Long, e Allen (1990), a Social Exchange Theory permite explicar a relação entre os benefícios individuais e as percepções do desenvolvimento económico proporcionado pelo turismo. Os residentes estão disponíveis para participar nessa relação se acreditarem que os benefícios que obterão são superiores aos custos decorrentes da actividade turística no seu local de residência (ANDEREK et al, 2005; GURSOY e RUTHERFORD, 2004; GURSOY, JUROWSKI e UYSAL, 2002; TEYE et al, 2002).

As diferenças de atitudes dos residentes face ao turismo, identificadas em estudos baseados na Social Exchange Theory, estão relacionadas com o nível de desenvolvimento turístico da região (LONG, PERDUE e ALLEN, 1990), os impactes económicos percebidos (WILLIAMS e LAWSON, 2001), a forte concentração de turistas em determinados lugares (MADRIGAL, 1995), o tempo de residência na região e naturalidade do residente (SHELDON e VAR, 1984), o grau de familiaridade com a actividade turística (LANKFORD, 1994), o contacto com turistas (AKIS, PERISTIANIS e WARNER, 1996), o impacte nos tempos de lazer (LANKFORD, 1994), o nível de desenvolvimento do destino e do país (SHELDON E ABENOJA, 2001; TEYE, SIRAKAYA e SÖNMEZ, 2002) e o tipo de desenvolvimento turístico (RYAN e MONTGOMERY, 1994).

De um modo geral, o predomínio de atitudes positivas face ao turismo por parte dos residentes é um indício de que o desenvolvimento turístico da região é adequado às condições locais (Lepp, 2006). Apesar de existem estudos no âmbito da literatura do turismo que fundamentam esta hipótese, outros, porém, mostram-se menos conclusivos (AP, 1992; GURSOY et al, 2002; JUROWSKI et al, 1997; LINDBERG e JOHNSON, 1997; MCGEHEE e ANDERECK, 2004). Contudo, múltiplas variáveis têm vindo a ser utilizadas para explicar as atitudes dos residentes face ao turismo, entre as quais se destacam o usufruto de infraestruturas e de benefícios, participação no processo de tomada de decisão, fase do ciclo de vida do destino, tipo de turismo, dependência económica do turismo e diferenças culturais entre residentes e turistas (LAWSON et al, 1998). 
Numa grande variedade de comunidades, os residentes estão geralmente receptivos à actividade turística desde que esta represente uma importante fonte de desenvolvimento económico para a região (BESCULIDES et al., 2002; BESTARD et al, 2006). Contudo, tal posição não implica que não existam reservas e preocupações relativamente aos efeitos na sua comunidade (ANDERECK et al, 2005).

Em conformidade com o quadro teórico-conceptual proporcionado pela Social Exchange Theory, a maioria dos estudos tem permitido concluir que os residentes que dependem da indústria turística, ou que esperam obter benefícios pessoais desta actividade, tendem a revelar atitudes mais positivas (BRUNT e COURTNEY, 1999; HARALAMBOPOULOS e PIZAM, 1996; JUROWSKI et al, 1997; LANKFORD e HOWARD, 1994; MCGEHEE e ANDERECK, 2004; SIRAKAYA, TEYE e SÖNMEZ, 2002). Do mesmo modo, resulta claro que todos estão conscientes de alguns impactes negativos (KING et al, 1991; MCGEHEE e ANDERECK, 2004).

\section{Contexto}

Localizado na zona oeste do Algarve, o Arade é uma sub-região de um dos principais destinos turísticos de Portugal. Constituído por quatro municípios, Lagoa, Monchique, Portimão e Silves (Figura 1), ocupa 30\% do território da região e alberga cerca de $30 \%$ da população algarvia. Na região do Arade está concentrada cerca de $25 \%$ da oferta turística.

Os municípios de Portimão e Lagoa têm a maior faixa litoral do Arade e, por isso, o turismo Sol e Praia constitui a sua vocação principal. Monchique e Silves, por seu lado, essencialmente localizados no interior, têm na natureza e no património histórico-cultural os seus principais recursos turísticos. 


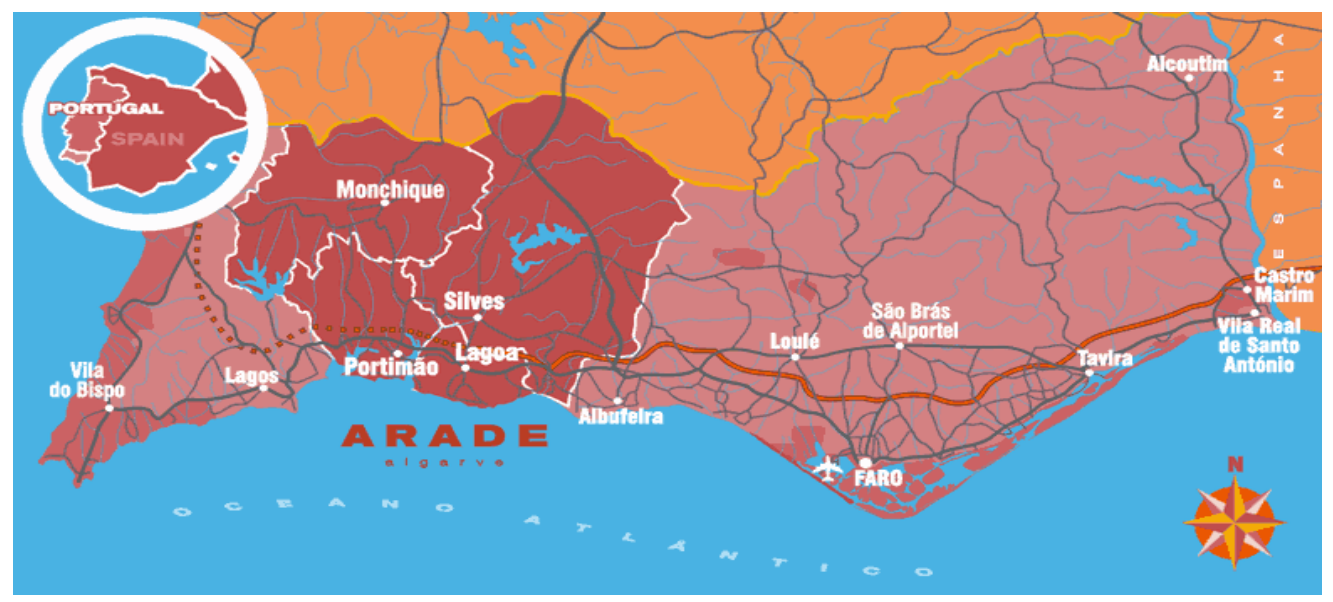

Figura 1- A Região do Arade no mapa do Algarve

\section{Metodologia}

\subsection{Recolha de dados}

O inquérito aos residentes foi aplicado nos municípios de Silves, Portimão, Lagoa e Monchique e teve como população alvo todos os residentes com mais de 15 anos, de acordo com os dados do Recenseamento Geral da População e Habitação de 2001.

$\mathrm{O}$ número de indivíduos a incluir em cada quota foi determinado proporcionalmente ao número de residentes nos respectivos concelhos e freguesias, em cada escalão etário.

Em cada sub-amostra procurou-se que existisse um número mínimo de entrevistados suficiente para possibilitar que se efectuassem alguns testes estatísticos considerados relevantes face ao objectivo do estudo.

Ficou assim definida uma amostra de 442 residentes a inquirir, distribuída pelos quatro concelhos. Os questionários foram implementados por entrevista directa, nos meses de Julho e Agosto de 2004, tendo por base um questionário estruturado.

\subsection{Representatividade da amostra}

A definição da amostra de residentes a inquirir baseou-se no método de amostragem por quotas independentes. As quotas foram determinadas proporcionalmente à distribuição dos residentes pelos quatro municípios que constituem o ARADE e, também, atendendo à sua distribuição por sexo e por escalão etário. Deste modo, a amostra reflecte a distribuição da população alvo no que respeita a estes três elementos fundamentais, com base nas estatísticas do INE (Dados do Recenseamento Geral da População e Habitação de 2001). 
Na sequência destes procedimentos foi possível obter uma amostra suficientemente grande, o que possibilitou levar a cabo as análises estatísticas pretendidas, e simultaneamente representativa dos diferentes extractos caracterizadores da população alvo. Os resultados dos testes à aleatoriedade das observações relativas às características sócio-demográficas dos residentes inquiridos (sexo, idade, tempo de residência no concelho, estado civil, grau de instrução e profissão) permitem concluir sobre a não rejeição da hipótese de aleatoriedade na distribuição de cada uma destas variáveis (testes aos "Runs": $p>0,05$ ).

\subsection{Tratamento de dados}

Os dados recolhidos através da implementação do questionário junto das amostras definidas foram sujeitos a um tratamento estatístico tendo por base essencialmente medidas de estatística descritiva. Trata-se de uma análise feita questão a questão e complementada por cruzamentos de variáveis considerados pertinentes face aos objectivos do estudo. Foram efectuados testes estatísticos ao relacionamento entre algumas variáveis. De entre os testes efectuados destacam-se os Testes do Chi-Quadrado $\left(X^{2}\right)$, os Testes $t$ para as duas amostras independentes e os Testes de Kruskall-Wallis.

A análise dos resultados foi desenvolvida no software estatístico Statistical Package for Social Sciences (SPSS), versão 12.0, tendo todos os testes estatísticos sido efectuados para um nível de significância de 5\%.

\section{Resultados}

\subsection{Caracterização da Amostra}

Os residentes inquiridos eram moradores nos municípios de Portimão (43\%), Silves (30\%), Lagoa (20\%) e Monchique (7\%), 92\% são portugueses e cerca de $83 \%$ residem no concelho há mais de 10 anos. A maior parte são casados (63\%) ou solteiros $(27 \%)$ e a média de idades dos respondentes situa-se nos 45 anos $(44,67)$. No município de Monchique a média de idades é a mais elevada - cerca de 55 anos. Em oposição, o município de Lagoa é aquele onde a média das idades é a mais baixa - 42 anos.

No que diz respeito ao nível de instrução da população residente inquirida, mais de três quartos possuem um grau académico de nível básico (33\%) ou secundário (52\%). Apenas $15 \%$ dos inquiridos possuem qualificações ao nível do ensino superior. Cerca de $68 \%$ dos 
indivíduos inquiridos no município de Monchique são portadores do nível de ensino mais baixo.

A maioria da população respondente exerce uma actividade profissional que envolve o contacto directo com turistas (63\%), muito embora $72 \%$ afirme não ter no turismo a sua principal fonte de rendimento. É no município de Silves que a população inquirida desempenha actividades laborais que envolvem um menor contacto directo com turistas (48\%). Em oposição, nos municípios de Portimão e de Lagoa existe uma relação mais directa entre o trabalho dos residentes inquiridos e o contacto directo com turistas $(70 \%$ e $64 \%$, respectivamente), sendo nestes dois municípios que uma parte significativa da população inquirida tem no turismo a sua principal fonte de rendimento.

Em termos gerais, cerca de $64 \%$ da população afirma não ter elementos do seu agregado familiar a trabalhar no turismo. No entanto, nos municípios onde a actividade turística é mais intensa, Portimão (43\%) e Lagoa (45\%), uma fatia considerável da população residente inquirida tem elementos do agregado familiar a desempenhar actividade profissional no turismo. Os moradores nos municípios de Monchique e de Silves mantêm, nestes domínios, um envolvimento marginal com a actividade turística.

\subsection{Importância e Satisfação com os Atributos do Destino}

Pretendeu-se conhecer a importância que a população residente inquirida confere a um conjunto de 30 atributos associados ao destino turístico e a respectiva satisfação em relação aos mesmos atributos. O grau de importância dos 30 atributos foi medido através de uma Escala de Likert com cinco níveis em que 1-Nada Importante, 2-Pouco Importante, 3Importante, 4-Bastante Importante e 5-Extremamente Importante. O grau de satisfação com os mesmos atributos foi medido através da mesma tipologia de escala em que 1-Muito Insatisfeito, 2-Insatisfeito, 3-Nem Satisfeito Nem Insatisfeito, 4-Satisfeito, 5-Muito Satisfeito. Em ambos foi contemplada a opção Sem Opinião.

No caso da importância e da satisfação com os atributos, verifica-se uma certa unanimidade no que diz respeito à forma como os inquiridos encaram o destino turístico enquanto entidade compósita. Em termos médios, os inquiridos atribuem níveis superiores de importância à generalidade dos atributos quando comparados com a satisfação em relação aos mesmos. As "Praias", “Acessibilidades", "Hospitalidade", "Sinalização", "Limpeza”, "Recolha de lixo", "Abastecimento de águas", "Parques de estacionamento", "Competência e cortesia dos 
residentes", "Jardins e espaços verdes" e "Segurança pública" são os atributos considerados mais importantes no contexto do destino turístico onde residem, todos com uma ponderação média superior a 4. Por seu turno, a satisfação média mais elevada, apesar de não atingir este nível da escala, diz respeito aos atributos "Praias", "Hospitalidade" e "Gastronomia".

Entre os atributos menos valorizados pelos residentes neste contexto encontram-se as "termas", as "zonas comerciais", os "monumentos" e os "circuitos pedonais". Os "Parques de estacionamento", o "Trânsito", o "Planeamento urbanístico" e os "Jardins e espaços verdes" são objecto de menor satisfação por parte dos residentes nos quatro municípios.

Tabela 1 - Grau de Importância e de Satisfação com os atributos

\begin{tabular}{|lcccc}
\hline \multirow{2}{*}{ VARIÁvEL } & \multicolumn{2}{c}{ IMPORTÂNCIA } & \multicolumn{2}{c}{ SATISFAÇÃo } \\
\cline { 2 - 5 } & MÉDIA & $\begin{array}{c}\text { DESVIO } \\
\text { PADRÃo }\end{array}$ & MÉDIA & $\begin{array}{c}\text { DESVIO } \\
\text { PADRÃo }\end{array}$ \\
\hline Praias & $\mathbf{4 , 0 7}$ & 0,927 & $\mathbf{3 , 9 4}$ & 0,906 \\
Termas & 3,21 & 1,056 & 3,28 & 0,899 \\
Hospitalidade & $\mathbf{4 , 0 2}$ & 0,825 & $\mathbf{3 , 6 1}$ & 0,862 \\
Autenticidade & 3,76 & 0,858 & 3,31 & 0,893 \\
Acessibilidades & $\mathbf{4 , 2 1}$ & 0,844 & 2,77 & 1,116 \\
Centros históricos & 3,65 & 0,898 & 3,03 & 0,967 \\
Trânsito & 3,64 & 1,025 & 2,59 & 1,022 \\
Meios de transporte & 3,84 & 0,909 & 2,81 & 1,026 \\
Infra-estruturas desportivas & 3,66 & 0,896 & 2,91 & 1,098 \\
Paisagem & 3,99 & 0,880 & 3,24 & 1,068 \\
Monumentos & 3,64 & 0,929 & 3,02 & 0,984 \\
Planeamento Urbanístico & 3,80 & 0,953 & 2,65 & 1,040 \\
Restauração & 3,77 & 0,859 & 3,23 & 0,956 \\
Arquitectura tradicional & 3,61 & 0,915 & 2,91 & 0,993 \\
Animação & 3,71 & 0,883 & 2,91 & 1,022 \\
Alojamento & 3,86 & 0,856 & 3,29 & 0,922 \\
Zonas comerciais & 3,50 & 0,917 & 3,28 & 0,981 \\
Eventos culturais & 3,71 & 0,859 & 2,91 & 1,025 \\
Informação turística & 3,84 & 0,859 & 2,97 & 0,985 \\
Gastronomia & 3,84 & 0,869 & $\mathbf{3 , 6 4}$ & 0,900 \\
Locais de lazer & 3,91 & 0,856 & 2,84 & 1,049 \\
Segurança pública & $\mathbf{4 , 3 0}$ & 0,860 & 2,80 & 1,128 \\
Jardins e espaços verdes & $\mathbf{4 , 1 8}$ & 0,860 & 2,55 & 1,129 \\
Circuitos pedonais & 3,64 & 0,940 & 2,72 & 1,052 \\
Competência e cortesia & $\mathbf{4 , 1 2}$ & 0,887 & 3,39 & 0,939 \\
Parques de estacionamento & $\mathbf{4 , 1 4}$ & 0,854 & 2,30 & 1,110 \\
Abastecimento de águas & $\mathbf{4 , 1 9}$ & 0,826 & 3,32 & 0,962 \\
Recolha de lixo & $\mathbf{4 , 2 7}$ & 0,862 & 3,21 & 1,022 \\
Limpeza & $\mathbf{4 , 3 1}$ & 0,830 & 3,05 & 1,041 \\
Sinalização & $\mathbf{4 , 1 1}$ & 0,858 & 2,90 & 1,091 \\
\hline & & & &
\end{tabular}

O modo como os residentes ponderam a importância dos atributos em análise é influenciada pelo facto de desempenharem actividades profissionais que implicam o contacto directo com turistas (testes $t$ para duas amostras independentes: $p<0,05$ ). Esta relação não existe apenas em relação a alguns atributos: "Termas", "Meios de transporte", "Infra-estruturas 
desportivas", "Monumentos", "Planeamento urbanístico" e "Competência e cortesia". Esta relação também não se verificou relativamente aos graus de satisfação com os mesmos atributos (testes $t$ para duas amostras independentes: $\mathrm{p}>0,05$ ).

O modo como a população inquirida pondera a importância dos atributos em análise é influenciada pelo facto do respondente ter ou não no turismo a sua principal fonte de rendimento. Existem diferenças significativas na valorização dos atributos "Praias", "Hospitalidade", "Acessibilidades", "Arquitectura tradicional", "Limpeza" e "Sinalização" (teste $t$ para duas amostras independentes: $\mathrm{p}<0,05$ ). Esta variável não influencia, no entanto, de modo significativo a satisfação dos residentes com os atributos em análise (com excepção do atributo "Trânsito").

O facto dos respondentes terem algum elemento do agregado familiar a trabalhar no turismo não se reflecte na forma como os residentes ponderam a importância do conjunto dos atributos (testes $t$ para duas amostras independentes: $p>0,05$ ). Esta situação é reproduzida de forma idêntica quando se analisa a satisfação dos residentes. Os atributos relativamente aos quais se detectaram diferenças significativas entre respondentes com e sem algum elemento do agregado familiar a desempenhar actividades profissionais no turismo prendem-se com o "Planeamento urbanístico", as "Infra-estruturas desportivas", os "Jardins e espaços verdes" e os "Locais de lazer".

O facto do respondente desenvolver uma actividade profissional ligada ao turismo influencia a satisfação dos residentes com os atributos em análise. Neste caso, detectaram-se diferenças estatisticamente significativas de satisfação no caso das "Termas", "Trânsito", "Meios de transporte", "Planeamento urbanístico" e "Parques de estacionamento" (testes $t$ para duas amostras independentes: $\mathrm{p}<0,05)$.

O estudo da importância e da satisfação com os atributos desagregado em função do município de residência revela diferenças com significado do ponto de vista estatístico (Figura 2). 


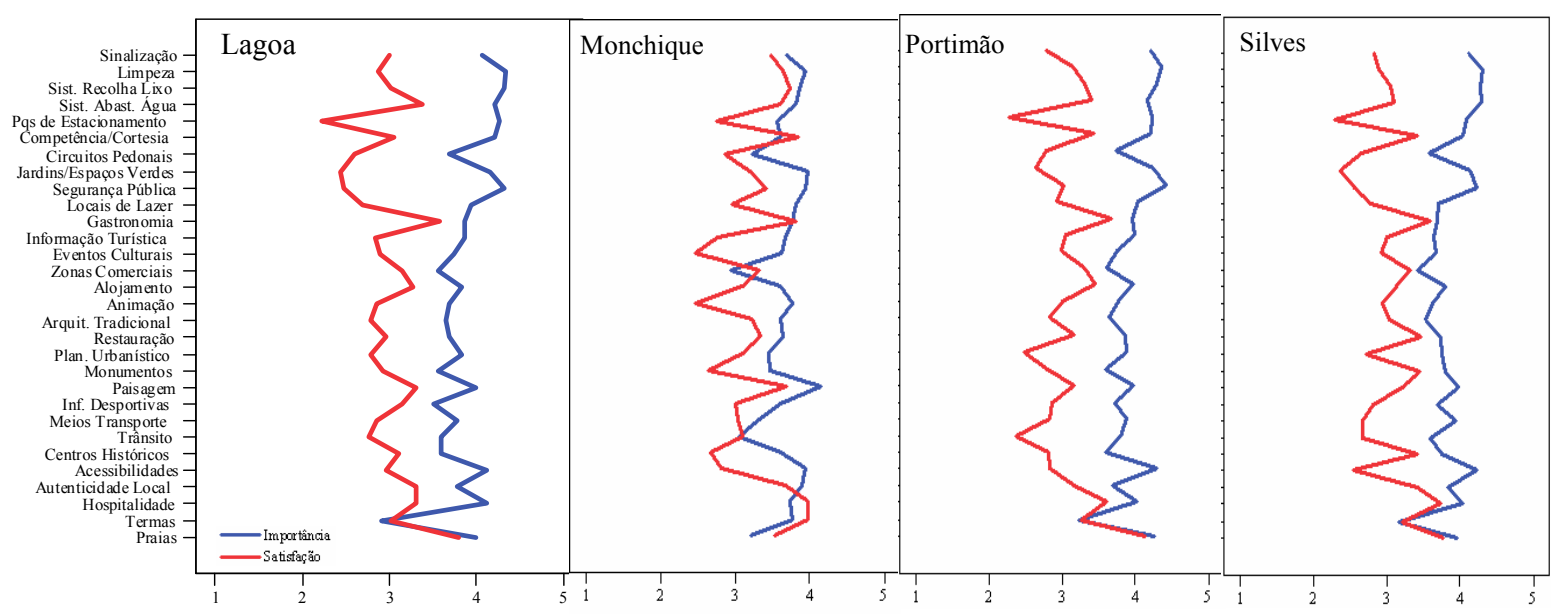

Figura 2 - Grau de Importância e de Satisfação com os atributos nos quatro municípios

À excepção dos atributos "Termas" e "Praias", os residentes inquiridos no município de Lagoa atribuem níveis de importância e de satisfação distintos aos vários atributos estudados. O atributo "Termas" é, para estes residentes, o menos importante. As "Praias", "Gastronomia" e "Sistema de abastecimento de água" são os atributos que reúnem os graus de satisfação mais elevados. No sentido oposto, os atributos em relação aos quais os inquiridos se revelam visivelmente menos satisfeitos são os "Parques de estacionamento", "Jardins e espaços verdes" e "Segurança pública".

Para os residentes em Portimão, apenas os atributos "Praias" e "Termas" são coincidentes em termos de importância e de satisfação. Neste caso, os diferentes atributos estudados assumem uma importância relativa bastante homogénea com uma forte concentração de opiniões no nível 4 da escala. "Termas" é o atributo menos importante. No que diz respeito à satisfação, os residentes inquiridos neste concelho revelam-se pouco satisfeitos com 13 dos 30 atributos estudados: "Sinalização", "Parques de estacionamento", "Circuitos pedonais", "Jardins e espaços verdes", "Segurança", "Locais de lazer", "Arquitectura tradicional”, "Planeamento urbanístico", "Infra-estruturas desportivas" e "Meios de transporte". "Praias" é o atributo em relação ao qual os graus de satisfação são mais elevados.

Monchique é o único município onde se verificam níveis de satisfação superiores aos níveis de importância. Esta situação ocorre em relação aos atributos "Praias", "Termas", "Hospitalidade", "Zonas comerciais", "Gastronomia", "Trânsito" e "Competência e cortesia". "Paisagem", "Circuitos pedonais", "Limpeza", "Autenticidade", “Acessibilidades" e “Termas” são atributos cuja importância é geralmente reconhecida pelos inquiridos (de referir 
que um dos principais produtos turísticos deste município é precisamente as termas). Pelo contrário, as "Praias", "Trânsito" e "Zonas comerciais" são considerados atributos menos importantes. Os níveis de satisfação inferiores são atribuídos aos "Centros históricos", "Monumentos", “Animação", "Eventos culturais" e "Parques de estacionamento". "Termas", "Hospitalidade", "Gastronomia" e "Competência e cortesia" são os atributos fonte de maior satisfação por parte dos inquiridos.

Relativamente aos residentes no município de Silves, os atributos "Gastronomia", "Hospitalidade", "Termas" e "Praias" revelam coincidência na forma como são apreciados pelos residentes inquiridos, tanto em termos de importância como de satisfação. A maior importância relativa é atribuída à "Sinalização", "Limpeza", "Sistema de recolha de lixo", "Sistema de abastecimento de águas", "Jardins e espaços verdes", "Segurança" e "Acessibilidades". O atributo "Termas" é o menos importante. Em termos gerais, em Silves os residentes encontram-se globalmente pouco satisfeitos com o desempenho dos atributos analisados. Pela positiva destacam-se apenas as "Praias", "Hospitalidade" e "Gastronomia". A sua insatisfação é visível sobretudo em relação às "Acessibilidades", "Jardins e espaços verdes", "Estacionamento", "Planeamento urbanístico", "Trânsito" e "Meios de transporte".

Em termos globais, a população residente nos municípios incluídos neste estudo considera-se satisfeita relativamente ao desempenho dos atributos analisados (Figura 3). Todavia, é de realçar o facto dos municípios de Portimão e Lagoa, os mais atingidos pela pressão turística, evidenciarem níveis superiores de insatisfação global.

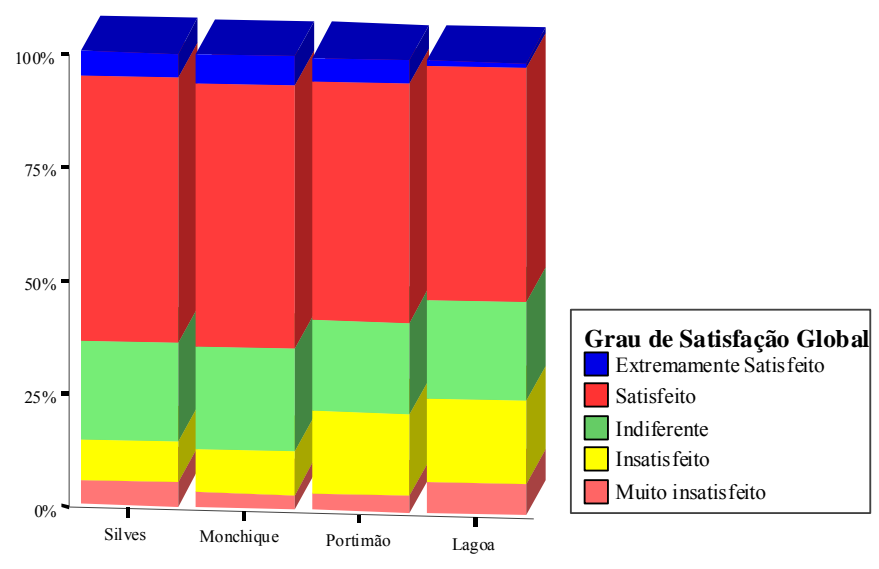

Figura 3 - Grau de satisfação global com os atributos turísticos do município de residência Desagregação por município de residência 


\subsection{Atitudes perante o turismo}

Com o objectivo de aferir as atitudes da população residente nos quatro municípios do ARADE relativamente ao sistema turístico, foi apresentado um conjunto de 23 afirmações em relação às quais era solicitado ao inquirido que expressasse o seu grau de concordância. Foi utilizada para o efeito uma Escala de Likert com cinco níveis, definidos do seguinte modo: 1Discordo totalmente, 2-Discordo, 3-Não Discordo Nem Concordo, 4- Concordo, 5-Concordo totalmente. Foi contemplada a opção Sem Opinião.

A Tabela 2 sintetiza a informação resultante do tratamento estatístico preliminar do conjunto das afirmações em análise.

Tabela 2 - Atitudes perante o turismo

\begin{tabular}{|lcc}
\hline VARIÁVEL & MÉDIA & DESVIO PADRÃO \\
\hline 1- O turismo cria mais emprego para residentes. & 4,08 & 0,876 \\
2- O turismo tem trazido mais riqueza para o concelho. & 3,67 & 0,905 \\
3- O seu rendimento tem melhorado graças ao turismo. & 3,12 & 1,156 \\
4- Os preços ... subiram graças ao turismo. & 3,88 & 1,023 \\
5- O turismo beneficia apenas um pequeno número de residentes. & 3,44 & 1,102 \\
6- Os turistas gastam pouco dinheiro neste concelho. & 3,56 & 0,944 \\
7- É interessante conhecer turistas. & 4,02 & 0,756 \\
8- O turismo é a principal razão para construção de piscinas ... & 3,39 & 1,215 \\
9- Por causa dos turistas há mais animação cultural no concelho. & 3,34 & 1,092 \\
10- O turismo contribui para manter vivas as tradições... & 3,63 & 0,965 \\
11- O turismo prejudica a qualidade de vida dos residentes. & 2,47 & 1,050 \\
12- Devido ao turismo, a criminalidade aumentou... & 2,67 & 1,127 \\
13- O turismo tem contribuído para conservar o património ... & 3,26 & 1,051 \\
14- No verão, os serviços ... de água e energia funcionam pior. & 3,24 & 1,083 \\
15- Se não fosse o turismo, as estradas ... seriam piores. & 3,39 & 1,023 \\
16- O turismo é o principal responsável problemas trânsito... & 2,80 & 1,086 \\
17- O turismo é o principal responsável problemas ruído... & 2,68 & 1,056 \\
18- O turismo é o principal responsável problemas poluição.. & 2,61 & 1,016 \\
19- A construção de hotéis e outras infra-estruturas turísticas... & 3,46 & 1,190 \\
20- O turismo tem contribuído para conservar espaços naturais & 3,29 & 1,040 \\
21- O elevado no turistas afasta residentes de lugares públicos. & 2,47 & 1,001 \\
22- Em geral, turismo traz mais benefícios que custos... concelho. & 3,62 & 0,985 \\
23- Em geral, turismo traz mais benefícios que custos... Algarve. & 3,95 & 0,896 \\
\hline
\end{tabular}

A análise dos dados aponta para uma atitude geral bastante favorável da população residente no ARADE face ao turismo, sendo que o nível médio de concordância face às 23 afirmações apresentadas aos residentes inquiridos ilustra uma tendência para os respondentes se posicionarem entre os níveis 2 e 4 da escala. Os níveis superiores de discordância encontramse associados às afirmações que traduzem possíveis efeitos negativos da actividade turística. Entre estas afirmações podem destacar-se as seguintes: "o turismo prejudica a qualidade de vida dos residentes", "devido ao turismo a criminalidade aumentou no concelho", "o turismo 
prejudica a qualidade de vida dos residentes", "o elevado número de turistas afasta os residentes dos locais públicos", “o turismo é o principal responsável pelos problemas de poluição, de ruído e de poluição no concelho".

São sobretudo as mulheres que concordam que "o turismo beneficia apenas um pequeno número de respondentes (teste $t$ para duas amostras independentes: $\mathrm{p}=0,02$ ).

As atitudes em relação ao turismo variam, em alguns itens, com o grau de instrução dos inquiridos relativamente às seguintes afirmações: "O seu rendimento tem melhorado graças ao turismo", "A construção de infra-estruturas turísticas tem vindo a destruir a paisagem natural", "O turismo é o principal responsável pelos problemas de ruído no concelho" e "Se não fosse o turismo, as estradas do concelho seriam piores" (testes de Kruskal Wallis: $\mathrm{p}<$ 0,05). É de referir que os respondentes com nível de formação superior tendem a atribuir um nível de concordância superior a estas quatro afirmações.

Verificou-se que os indivíduos cujo trabalho está ligado ao turismo apresentam uma atitude globalmente mais favorável relativamente ao turismo, sobretudo no caso dos seguintes itens: "O turismo beneficia apenas um pequeno grupo de residentes", "O turismo cria mais empregos para residentes" (testes $t$ para duas amostras independentes: $p<0,02$ ).

O facto do residente ter no turismo a sua principal fonte de rendimento traduz-se numa atitude mais favorável em relação à actividade turística na sua comunidade. Esta tendência é visível, sobretudo, quando se pronunciam sobre as seguintes afirmações: "O turismo beneficia apenas um pequeno grupo de residentes", "O seu rendimento tem melhorado graças ao turismo" e "O turismo tem trazido mais benefícios do que custos para os residentes do concelho" (testes $t$ para duas amostras independentes: $\mathrm{p} \leqq 0,005)$.

Registaram-se, igualmente, algumas diferenças significativas de atitude consoante o inquirido tenha ou não algum elemento do agregado familiar a trabalhar no turismo (testes $t$ para duas amostras independentes: $\mathrm{p}<0,05$ ). Mais uma vez, os inquiridos ligados ao turismo, neste caso através de algum familiar que desempenha sua actividade profissional no sector turístico, reflectem, nestas afirmações, uma atitude mais positiva em relação à actividade turística. 


\section{Conclusão}

A análise dos dados permitiu concluir que nem sempre existe coincidência entre a importância reconhecida dos atributos da respectiva área de residência, aqui considerada enquanto destino turístico, e o grau de satisfação relativamente aos mesmos atributos.

Em termos gerais, os atributos considerados mais importantes pelos residentes inquiridos são as "Praias", “Acessibilidades", "Segurança”, "Jardins e espaços verdes”, "Cortesia dos profissionais", "Parques de estacionamento", "Sistema de fornecimento de água", "Sistema de recolha de lixo", "Limpeza urbana" e "Sinalização". Os atributos que os residentes consideraram menos importantes são os seguintes: "Termas", "Áreas comerciais", "Monumentos" e "Circuitos pedonais".

Outra conclusão interessante aponta para o facto de que a forma como os residentes ponderam a importância dos atributos ser influenciada por duas variáveis: dependência económica da actividade turística e grau de interacção com turistas. Em termos globais, todos os atributos são mais importantes para os residentes que mantêm um contacto regular com os turistas na região, bem como para os que, de algum modo, estão economicamente dependentes do turismo. $\mathrm{O}$ grau de contacto com turistas surge como uma das variáveis que mais influencia o modo como os residentes avaliam a actividade turística na sua comunidade.

A maioria dos residentes mostra-se globalmente satisfeita com o impacto do turismo na sua região (55\%). Contudo, cerca de $41 \%$ dos respondentes estão insatisfeitos com os impactes produzidos pela actividade turística. "Praias", "Competência e cortesia dos profissionais" e "Gastronomia" são os atributos em relação aos quais os residentes têm percepções mais positivas. Pelo contrário, os residentes inquiridos mostram-se menos satisfeitos com o "Trânsito", "Planeamento urbano", "Acessibilidades", "Jardins e espaços verdes" e "Parques de estacionamento".

Outra conclusão importante é o facto de que os residentes nos municípios litorais Portimão e Lagoa), alvo de maior procura turística sobretudo nos meses de verão, mostrarem-se globalmente menos satisfeitos com os impactes do turismo do que os residentes nos municípios do interior onde a pressão turística é inferior.

Espera-se, com os resultados obtidos através deste estudo, contribuir para uma tomada de decisão consequente em relação às expectativas dos residentes no ARADE. A insatisfação global manifestada sobretudo em relação a questões relacionadas com o ordenamento do 
território e o planeamento urbanístico deve constituir um sinal de alerta para os responsáveis que, quer a nível local quer regional, gerem esta área-destino.

Neste contexto, revela-se pertinente aprofundar o estudo da relação entre a satisfação da população com os atributos do destino turístico onde reside e as suas atitudes face à actividade turística.

\section{Referências Bibliográficas}

AKIS, S.; PERISTIANIS N.; WARNER, J. 1996. Residents' attitudes to tourism development: the case of cyprus. In: Tourism Management, 17: 481-494.

ANDERECK, K. L.; VOGT, C. A. 2000. The relationship between residents' attitudes toward tourism and tourism development options. Journal of Travel Research, 39, August: 27-36.

ANDERECK, K. L.; VALENTINE, K. M.; KNOPF, R. C.; VOGT, C. A. 2005. Residents' perceptions of community tourism impacts. Annals of Tourism Research, 32, 4: 1056-1076.

AP, J. 1992. Residents' perceptions on tourism impacts. Annals of Tourism Research. 19, 4: 665-690.

AP, J.; CROMPTON, J. L. 1993. Residents' strategies for responding to tourism impacts. Journal of Travel Research, 32,1: 47-50.

BESCULIDES, A.; LEE M. E.; McCORMICK, P. J. 2002. Residents' perceptions pf the cultural benefits of tourism. Annals of Tourism Research, 29, 2: 303-319.

BESTARD, A. B.; NADAL, J. R. 2006. Modelling environmental attitudes toward tourism. Tourism Management, 28, 3: 688-695.

BRUNT, P ; COURTNEY, P. 1999. Host perceptions of sociocultural impacts. Annals of Tourism Research, 26: 493-515.

DAVIS, D.; ALLEN, J.; COSENZA, R. M. 1988. Segmenting local residents by their attitudes, interests and opinions toward tourism. Journal of Travel Research, 27, 2: 2-8.

FREDLINE, E.; FAULKNER, B. 2000. Host community reactions: a cluster analysis. Annals of Tourism Research, 27, 3: 763-784.

GURSOY, D.; RUTHERFORD, D. G. 2004. Host attitudes toward tourism: an improved structural model. Annals of Tourism Research, 31, 3: 495-516.

GURSOY, D.; JUROWSKI C.; UYSAL, M. 2002. Resident attitudes: a structural modeling approach. Annals of Tourism Research, 29, 1: 79-105.

HARALAMBOPOULOS, N.; PIZAM, A. .1996. Perceived impacts of tourism: the case of Samos. Annals of Tourism Research, 23, 3: 503-526.

JUROWSKI, C.; UYSAL, M.; WILLIAMS, R. D. 1997. A theoretical analysis of host community resident reactions to tourism. Journal of Travel Research, 36, 2: 3-11.

KING, B.; PIZAM, A.; MILMAN, A. 1991. Social impacts of tourism: host perceptions. Annals of Tourism Research, 20: 650-665.

KO, D. W.; STEWART, W. P. 2002. A structural equation model of residents' attitudes for tourism development. Tourism Management, 25: 521-530.

LANKFORD, S. V.; HOWARD, D. R. 1994. Developing a tourism impact attitude scale. Annals of Tourism Research, 21: 121-139. 
LANKFORD, S. V. 1994. Attitudes and perceptions toward tourism and rural regional development. Journal of Travel Research, 32,3: 35-43.

LAWSON, L. J.; WILLIAMS, J.; YOUNG, T.; COSSENS, J. 1998. A comparison of residents' attitudes towards tourism in 10 New Zeland destinations. Tourism Management, 19, 3: 247-256.

LEPP, A. 2006. Residents' attitudes towards tourism in Bigodi village. Tourism Management, 28, 3: 876-885.

LINDBERG, K.; JOHNSON, R. L. 1997. Modelling resident attitudes toward tourism. Annals of Tourism Research, 24: 402-424.

LONG, P. T.; PERDUE, R.; ALLEN, L. 1990. Rural resident tourism perceptions and attitudes by community level of tourism. Journal of Travel Research, 23, 9: 3-9.

MADRIGAL, R. 1995. Residents' perceptions and the role of government. Annals of Tourism Research, 22: 86-102.

MCGEHEE, N.; ANDERECK, K. 2004. Factors predicting rural residents' support of tourism. Journal of Travel Research, 43: 131-140.

PERDUE, R. R.; LONG P. T.; ALLEN L. 1987. Rural resident tourism perceptions and attitudes. Annals of Tourism Research, 14: 420-429.

PERDUE, R. R.; LONG, P. T.; ALLEN L. 1990. Resident support for tourism development. Annals of Tourism Research, 17: 586-599.

RYAN, C.; MONTGOMERY, D. 1994. The attitudes of Bakewell residents to tourism and issues in community responsive tourism. Tourism Management, 15, 5: 358-369.

SHELDON, P. J.; ABENOJA, T. 2001. Resident attitudes in a mature destination: the case of Waikiki. Tourism Management, 22: 434-443.

SHELDON, P. J.; VAR, T. 1984. Resident attitudes to tourism in North Walles. Tourism Management, 5: 40-47.

SIRAKAYA, E.; TEYE, V.; SÖNMEZ, S. F. 2002. Understanding residents' support for tourism development in the Central Region of Ghana. Journal of Travel Research, 41: 57-67.

TEYE, V.; SIRAKAYA, E.; SÖNMEZ, S. F. 2002. Residents' attitudes towards tourism development. Annals of Tourism Research, 29, 3: 668-688.

WILLIAMS, J.; LAWSON, R. 2001. Community issues and resident opinions of tourism. Annals of Tourism Research, 28, 2: 269-290.

\section{Recebido em: 12/05/2008}

Aprovado em: 17/07/2008 